Purdue University

Purdue e-Pubs

Technology Leadership and Innovation Faculty Department of Technology Leadership and

Publications

Innovation

2019

\title{
Applying empathy-driven participatory research methods to higher education new degree development
}

Lisa Bosman

lbosman@purdue.edu

Abrar Hammoud

Sandhya Arumugam

Follow this and additional works at: https://docs.lib.purdue.edu/tlipubs

\section{Publisher Citation}

Lisa Bosman, Abrar Hammoud, Sandhya Arumugam, (2019) "Applying empathy-driven participatory research methods to higher education new degree development", Information Discovery and Delivery, Vol. 47 Issue: 1, pp.17-24.

This document has been made available through Purdue e-Pubs, a service of the Purdue University Libraries. Please contact epubs@purdue.edu for additional information. 


\title{
Applying Empathy-Driven Participatory Research Methods to Higher Education New Degree Development
}

\begin{abstract}
- Purpose: Innovation and entrepreneurship are economic drivers promoting competition and growth among organizations throughout the world, many of which would not exist without well-established new product development processes coupled with intentional and strategic focus on research and development. New product development processes, such as the lean start-up methodology and design thinking, are well-known and thriving as a result of empirically-grounded research efforts. Unfortunately, educational institutions and educational researchers, alike, are lagging when it comes to new program/degree development processes. Although the quantity of new degree offerings has increased substantially over the past several decades (in particular for multidisciplinary, interdisciplinary, and transdisciplinary programs), limited research has been conducted to document key procedures associated with the creation of new degree programs. The purpose of this study is to show one approach to how students can be used within the new program development process.
\end{abstract}

- Methodology: This approach uses participatory research, wherein students act as researchers and actively participate in the data collection and analysis process. Under the umbrella of participatory research, the study uses photo-voice, photo-elicitation, and focus groups for collecting qualitative data.

- Findings: Results suggest that students in one transdisciplinary studies in technology program value the following key attributes: (1) learning style (agency and choice, active hands-on learning, and real-world applications) and (2) learning context (technology and design focused assignments, integration of humanities, and self-selected disciplines of interest).

- Research Implications: Recommendations are provided for various higher education benefactors of the user-generated data including administration, faculty, marketing, recruitment, advisors, and the students, themselves.

Key Words: photo-voice, new degree development, innovation, student researchers, participatory research, interdisciplinary 


\section{Introduction}

\subsection{Problem Identification}

Innovation, design, and entrepreneurship are economic drivers promoting competition and growth to many for-profit firms in the United States, none of which would exist without well-established new product development processes and an intentional and strategic focus on research and development (Brown, 2009, Drucker, 1998). New product development processes, such as the lean start-up methodology and design thinking, are well known and thriving due to the vast amount of empirically-grounded research (Sattayaraksa and Boon-Itt, 2016, Colombo et al., 2015).

Unfortunately, educational institutions and researchers, alike, are lagging when it comes to new program/degree development processes. Although the quantity of new degree offerings has increased substantially over the past several decades (in particular for multidisciplinary, interdisciplinary, and transdisciplinary programs), limited research has been conducted to document key procedures associated with the creation of new programs (Knight et al., 2013). Fortunately, many new program development concepts can be inferred from the established new product development processes (Sweet et al., 2017), such as gaining empathy in the humancentered design process. Yet, due to the many stakeholders involved in starting a new program (e.g., administration, faculty, staff, students, industry) and the many facets differentiating higher education from its industry counterparts, research and guidance is necessary for educational institutions to effectively and efficiently develop and/or improve cross-disciplinary, value-added academic programs.

\subsection{Prior Approaches to Solving the Problem}

Although limited processes and procedures are available to higher education showing how new program development should be done, there is a wealth of literature describing why new program development is important, especially for new multidisciplinary, interdisciplinary, and transdisciplinary programs, providing oversight about the benefits to developing new programs.

A number of studies are available which identify advantages to students who participate in multidisciplinary, interdisciplinary, and transdisciplinary programs. Students develop higher levels of cognitive processing and critical thinking (Ivanitskaya et al., 2002), report positive attitudes toward literacy (Lattuca et al., 2017), improve research skills (Cowden and Santiago, 2016)and display high levels of teamwork and leadership skills (Mars, 2015). This is by no means accidental. Instead, a recent study by Borrego and Newswander (2010) suggests faculty are intentional about improving specific student learning outcomes when developing new multidisciplinary, interdisciplinary, and transdisciplinary programs. The authors conducted a content analysis of 129 successfully awarded interdisciplinary studies proposals to the National Science Foundation; they discovered five focus areas for student learning outcomes specific to interdisciplinary graduate education including content integration, teamwork, critical awareness, communication, and disciplinary grounding. 
Yet, challenges associated with new program development still remain. Herz and colleagues (2011) designed a undergraduate degree program in bioengineering which included an interdisciplinary emphasis on experiential learning and innovation; the authors cite a number of program development challenges including balancing curriculum breadth and depth, incorporating changes while keeping stability, and operating under the university umbrella rather than being located within a specific department.

\subsection{Remaining Gaps to Solving the Problem and Purpose of this Study}

Gantogtokh and Quinlan (2017) analyzed two interdisciplinary programs to identify challenges involved in the new program development process, suggesting workload, student heterogeneity, and coherence as key barriers. The authors conclude their study calling for academic researchers to be intentional and proactive about creating better strategies and approaches to new program development. Holley (2009) interviewed administrators, faculty, and doctoral students engaged in an interdisciplinary neuroscience program, which resulted in the identification of two key gaps in new program development: (1) traditionally, faculty are encouraged to be highly invested within an individual discipline or within their own department; this creates a hurdle for cross-disciplinary faculty collaboration, and (2) there is a need for an intentional and deliberate process to form and foster multidisciplinary integration. Richter and Paretti (2009) follow suit, stating "While numerous descriptions of interdisciplinary courses and projects appear in the literature, educators still lack rigorous research about learning barriers, outcomes, and concrete interventions to support this interdisciplinary development."

In summary, the literature provides motivation for the importance of developing new multidisciplinary, interdisciplinary, and transdisciplinary programs; this cross-disciplinary collaboration is an important strategy for extending knowledge and producing opportunities for new scholar inquiry associated with real-world problems (Wall and Shankar, 2008). Furthermore, in 2016, the National Science Foundation (NSF) identified "Growing Convergence Research" as a leading area for future NSF investments. The purpose of this study is to show one approach to the new program development process using students (e.g., the customer) in the data collection process. This approach uses participatory research, where students act as researchers and actively participate in the data collection and analysis process. The collective efforts of the research team respond to the following question: How can students be used in the information discovery and analysis process associated with new program development?

\section{Background}

\subsection{Participatory Action Research in Education}

Participatory action research (PAR) is a qualitative approach to research and inquiry where researchers work collaboratively with the participant subject population to collect data, reflect and take action (Mcintyre, 2007, Ozanne and Saatcioglu, 2008). Yasmeen (2016) conducted PAR in a college-level bio-statistics course in an attempt to improve student learning outcomes for what the author described as a "difficult, dry \& non-interesting" course taken by many students majoring in 
biological sciences; students collectively worked with the instructor to share their views, identify problems, and propose changes to the course. Wang and colleagues (2016) describe a study employing PAR to increase problem-based learning approaches within an undergraduate medical program, noting that the collaborative efforts of eight students, two tutors, and four educational researchers was a great benefit due to the triangulation of sources and continued member checking of information. Roberts and co-authors (2015) used PAR to understand issues associated with primary and secondary school absenteeism and low exam scores in Tanzania. Student-driven data collection revealed high teacher absenteeism, overcrowding, and lecture-based pedagogy as causes and the action component resulted in the development of an intensive after-school program centered around cooperative inquiry. Buck and peers (2013) used PAR with 30 elementary school girls to understand female perceptions of science and improve attitudes towards science education; data was collected and action ideas were generated through several focus-group interviews. Roberts (2018) explored the use of multimedia learning methods in teaching a variety of subjects common to the social sciences and business school, showing how PAR was employed to develop, apply and empirically test new teaching approaches with students.

\subsection{Photovoice in Higher Education}

Photovoice, commonly linked to participatory action research (PAR), occurs when participatory researchers use photography to offer new insights and perspectives toward making improvement (Wang and Burris, 1997, Kelly et al., 2018). In many cases the photos are supplemented with narrative or focus groups to further elicit understanding in a process coined photo-elicitation (Becke and Bongard, 2018, Copes et al., 2018). Stroud (2014) deployed photovoice as a pedagogical approach in undergraduate chemistry courses to promote student-centered learning through student presentations; the findings suggest an increase in student engagement and student learning outcomes. Mader and colleagues (2016) used photovoice and photo-elicitation to investigate student experiences in rural medical education training programs, noting that the PAR method allowed for greater depth in understanding lived experiences from student perspectives. Herbert and co-authors (2018) used photovoice and photo-elicitation to explore the needs of new and incoming community college students using a first-year seminar course requiring students to document their needs using photos and words. Walker and peers (2017) used photovoice to examine pre-service teachers likes and dislikes associated with the mandatory student teaching experience; the sixteen students took pictures, participated in two focus groups with the lead researcher, and developed an action plan to promote curriculum improvements. O'Neill and McMahon (2012) used photovoice to improve student feedback towards the evaluation and assessment of an undergraduate physiotherapy degree; group consensus was deployed to recommend solutions and take action. Kelly and colleagues (2018) used photovoice to investigate barriers to cross-cultural instruction where students actively participated by collecting images and documenting interpretations; the results suggested an increase in interest, engagement, and enthusiasm for the course. 


\subsection{Theoretical Contribution of this Study}

As evidenced in the Introduction section, the literature provides motivation for new program development within multidisciplinary, interdisciplinary, and transdisciplinary programs, implying benefits ranging from the development of critical thinking skills to enhanced student learning outcomes. Unfortunately, there are limited processes and procedures available to higher education showing how new program development should be done. Jumping ahead to the Background section, the literature is also filled with examples of how participatory action research (PAR) and photovoice have been applied to better understand need for improvement within general educational settings. Combining the two research areas, this study is the first, to the best of the authors knowledge, to focus on applying PAR and photovoice to new program development within higher education. Furthermore, it's the first to extend results beyond the basic program development and/or improvements, to provide recommendations for stakeholders and benefactors throughout higher education, including administration (e.g., Deans and Department Chairs), faculty, and various staff working in marketing, recruitment, and advising, to name a few.

\section{Methods}

\subsection{Participants}

Students enrolled in a newly offered bachelor's degree in transdisciplinary studies in technology were required to participate in the research as a class assignment. Eleven students participated in the study, including six females and five males. All participants were enrolled full-time at the research-intensive university located in the Midwest, U.S.A. Five of the participants were freshman, four were sophomores, and three were junior level students. The study design was approved by the university IRB \#1808020877 as Exempt Category (1). As a result, students were notified that the class assignment would be used for research purposes.

\subsection{Study Design and Data Collection}

The participatory research methods of photovoice and photo-elicitation, a qualitative approach, was deployed. Data collection required three main phases. First, students were given the assignment shown in Figure 1. Upon submission to the learning management system, a duplicate set of pictures and narratives were copied and stored on a common shared drive within a folder, which only the researchers could access. Second, the instructor placed photos anonymously and randomly into PowerPoint slides to prepare for the in-class discussion (a.k.a. focus group). An example of one of the slides is shown in Figure 2. Third, the instructor led a focus group session with the participants. Here, the SHOWED method (Gant et al., 2009), as shown in Table 1, was used to elicit further discussion and explanation from the pictures. An audio recording device captured participants' reflective, thought-provoking responses. The audio recording and transcribed discussion were stored on a common shared drive within a folder, which only the researchers could access. 
Step 1: Take 8 photos responding to your experience with the transdisciplinary studies in technology (TST) program, by specifically considering the following questions. Each question in the list should be exemplified through two pictures. Pictures must be taken by you (and not downloaded from the web). Think outside the box!

- What factors guided your decision to enroll in the TST program?

- What challenges or barriers exist that might negatively impact your participation in the TST program?

- What successes or motivations exist that positively impact your participation in the TST program?

- What recommendations can you offer that could/should be made to the TST program in an effort to increase your satisfaction, likelihood of completing a degree, and future employability?

Step 2: Insert all 8 photos into a Microsoft Word document. Under each photo, write a 3 to 5 sentence narrative explaining each photo and how it relates to the question.

Step 3: Place your name and assignment title in the header. Submit the Microsoft Word document to [the learning management system].

Figure 1: Photovoice Assignment

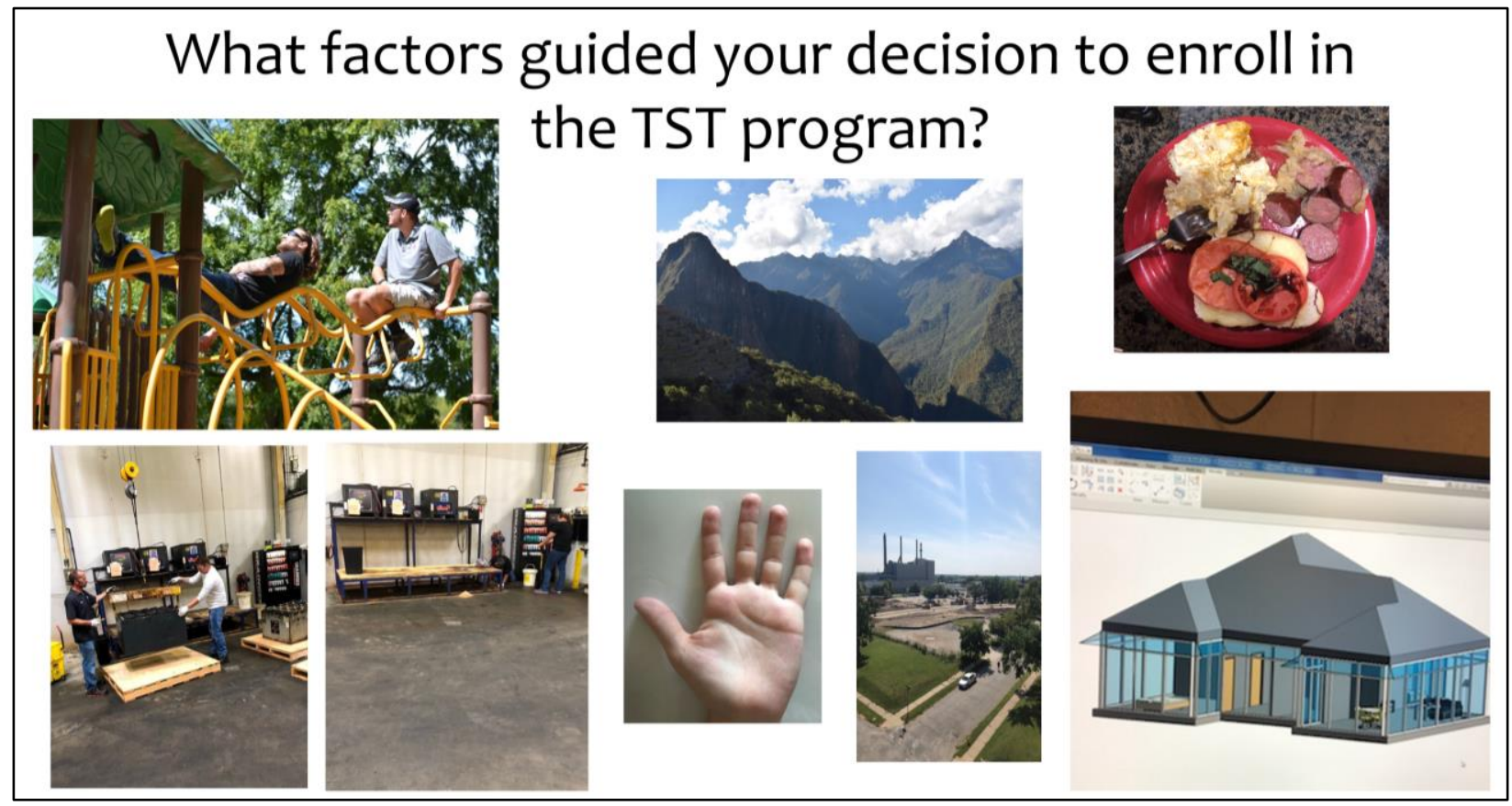

Figure 2: Example Focus Group Slide 
Table 1: SHOWED Method

\begin{tabular}{|c|l|}
\hline 1. & What do you See here? What is this photo about? \\
\hline 2. & $\begin{array}{l}\text { What is really Happening here? Why does this photo represent to } \\
\text { you? }\end{array}$ \\
\hline 3. & $\begin{array}{l}\text { How does this relate to Our lives? How does this challenge/barrier or } \\
\text { success/motivation impact your life? }\end{array}$ \\
\hline 4. & $\begin{array}{l}\text { Why does this concern, situation, strength exist? Why does this } \\
\text { challenge/barrier or success/motivation exist? What would } \\
\text { prevent/stop it from existing? }\end{array}$ \\
\hline 5. & $\begin{array}{l}\text { How can we become Empowered through our new understanding? } \\
\text { Now what? How can you overcome the challenge/barrier? How can } \\
\text { you leverage the success/motivation? }\end{array}$ \\
\hline 6. & $\begin{array}{l}\text { What can we Do? What are the next steps? What are your goals for } \\
\text { moving forward? }\end{array}$ \\
\hline
\end{tabular}

\section{Analysis and Results}

The NVivo 11 qualitative analysis software was used to analyze the photos, narratives, and transcripts. Due to the qualitative nature of the research, the goal of the analysis was to explore potential themes within the data. All data documents were imported into NVivo and the researchers read through the documents several times. The documents were coded and themes were identified. Analysis of the participatory research method led the researchers to identify four themes related to the new bachelor's degree in transdisciplinary studies in technology: (1) learning style, (2) learning context, (3) learning purpose, and (4) innovative approaches to learning. Due to the qualitative nature of the research, the goal of the analysis was to explore potential themes within the data.

\subsection{Theme 1: Learning Style}

The theme, learning style, includes the attributes of agency and choice, active hands-on learning, and real-world applications.

\subsubsection{Agency and Choice}

Participants reported that program agency and choice was a key factor for joining. [Note: The bachelor's degree in transdisciplinary studies in technology (TST) requires 120 credits to complete. About $1 / 3$ of the credits are core TST classes and the remaining credits are chosen by the students, within certain guidelines. Thus, the term agency and choice is associated with the freedom and flexibility for participants to define their own educational path.]

The freedom within the program motivates me to take hold of the reins of my education.

By the time I graduated, I had changed my mind a million times, which was okay because I had chosen the TST program, and that meant that I didn't have to choose just one thing. I could make my degree based on multiple majors. 
This is my main reason for joining TST because I felt I was good at multiple things and that I didn't want to just choose one.

Just like anything in life you need to work hard in order to be successful and I think this is especially important in this program because its not as guided as other exact curriculum classes and its more based on how much you put into it on how much you will get it.

[The program] provided me with the freedom to create my own schedule and try new things from all different places on campus.

\subsubsection{Active Hands-On Learning}

Participants reported the enjoyment and increased ability to learn when facilitated via active hands-on learning.

I wouldn't just be working on theory and math, I would be working with my hands.

Through all of the "What Kind of Learner Are You?" type of tests that you take throughout middle school and high school, I have always been shown that I am a hands-on learner.

I also enjoy the interactive side with field trips and experiments and movies we get to watch, as pictured here.

I also really like hands on activities whether it is field studies or making something with the $3 d$ print.

More technology in the class would also help in adding more hands-on activities in class.

\subsubsection{Real-World Applications}

Participants reported the enjoyment and increased ability to learn when conducted via real-world applications.

An amazing thing about the TST program is being able to create all these project ideas and then see them actually come to life.

This summer I went to a study abroad trip to Peru and I really enjoyed it. I think offering more collaboration programs or even traveling programs would be really good for the program, you learn these collaborative skills and communication.

This photo shows a wheelchair fun ramp design concept I created last year.

Below is a picture of a prosthetic leg I designed

This community garden/park concept was meant to be engaging, bring community together, and provide something for everyone. 


\subsection{Theme 2: Learning Context}

The theme, learning context, includes the attributes of technology and design focused assignments, integration of humanities, and self-selected disciplines of interest.

\subsubsection{Technology and Design Focused Assignments}

Participants reported the desire to work on more technology and design-focused assignments, increasing technical and analytical skills.

I wanted an education path that was technologically based, but sets me onto a platform that I can integrate technologies into every group from children to operating professionals.

I was craving to learn more technical skills.

The design itself was horribly flawed and not at all safe but I enjoyed going through the design process with it.

I was really proud of the $3 D$ modeling skills I learned in such a short time.

I am currently taking Intro to C programming, because I want to go into computer engineering.

I think seeing these kind of projects really encouraged me to want to continue with technology.

I knew that we would get to use fun softwares and technology. I love technology and I absolutely love messing around with new programs.

\subsubsection{Integration of Humanities}

Participants reported the longing to integrate the humanities through the development of artistic and writing skills, for example.

I also really like philosophy, and the intersection of human and technology.

I really think that there should be more nature related activities in the program.

Phenomology is a whole big thing that I didn't actively think about.

One thing we focused on a lot last year was journaling.

One of my major interests is art. This is a picture from one of the paintings I have just recently started.

You also understand how to bridge cultures and understand different perspectives.

Another thing that made me want to join the TST program was the idea of being able to combine these multiple disciplines by thinking holistically. For example, this picture shows 
only the flower in depth but not the whole city behind it which is allowing the flower to exist because of the watering system the city has implemented for the flower.

I would be more motivated to continue with the TST program if we practice soft skills which make us more adaptable, useful, and able to make a difference in the world.

\subsubsection{Self-Selected Disciplines of Interest}

Participants reported the benefit of going beyond technical depth to add context breadth through self-selected disciplines of interest.

The primary factor that led me to enroll in TST was my love for the interdisciplinary studies. I am double majoring in industrial design as well

She noticed from talking with me that I had many different interests, but no one career caught my eye.

There is lots of things I can learn to do if I choose to be a part of this major. I can combine many of my various interests into one course.

I think an important thing for me if I choose to pursue this major would be the ability to double major.

I chose to participate in the TST program because it gave me the opportunity to mix things that may not seem go together. While doing Animation, I can also have pieces of a Web Design degree.

This picture relates to TST for me by showing how you can have knowledge in many different areas (all the different objects on the wall) but still be able to combine them all (all of them fit in the painting).

\subsection{Theme 3: Learning Purpose}

Participants reported the choice of enrollment in this particular program as a way to prepare for a career. Participants stressed the importance and purpose of this learning approach has given them a leg up on their non-TST student peers.

I enjoy the few times we had professionals from industry come in to make critique, but that's the tone we should always be preparing for.

I hope to find a way to fuse all my interests into a cohesive skillset that will make me a more marketable job candidate.

The writing skills gained could be used to promote the TST program and let more employers know who we are!

I would also like a little more knowledge about what I can do with a degree like this. 
The TST doesn't just talk and experiment but shows us how the industry works that we are studying.

This job is really what got me into the TST program, because it showed me the importance of learning through doing.

This specific event was not too challenging but it gave me the most experience of what it is like in the workplace and how to deal with difficult problems.

I come from a business and construction background and I believe this major will greatly help me with that in my future by letting me personalize my path towards success.

I think this itself is a success because its saying that transdisciplinary is the future and I really think that's honestly the truth in terms of technology and even just the job industry in general.

\subsection{Theme 4: Innovative Approaches to Learning}

Participants reported the choice of enrollment in this particular program simply because of its focus on being different, new, and innovative.

It's new and it frankly never been done before.

It's such a hot topic right now!

I am motivated to continue with this program because, unlike the others, it feels like a blank slate, or an empty room that I can fill with anything I see fit.

I knew I would love learning in a way that is different than regurgitating information and standardized testing.

So far, I like that it is not in the traditional classroom setting.

The molding and evolving process of growing is a very prevalent, yet sensitive procedure that Ifelt that my education should be able to mimic, if not keep up with.

\section{Discussion}

\subsection{Summary of Findings}

The themes can be summarized into a story, as shown in Figure 3. The learning style (\#1) includes agency and choice, actives hands-on learning, and real-world applications, and the learning context (\#2) includes technology and design focused assignments, integration of humanities, and selfselected disciplines of interest. When these two (learn style and learning context) are combined, it provides students a sense of learning purpose (\#3), in that it offers an ideal route to career preparation. From a holistic perspective, the "equation" suggests an innovative approach to 
learning (\#4), which in itself offers a value proposition for students who simply desire to do things differently.

\section{Innovative Approaches to Learning}

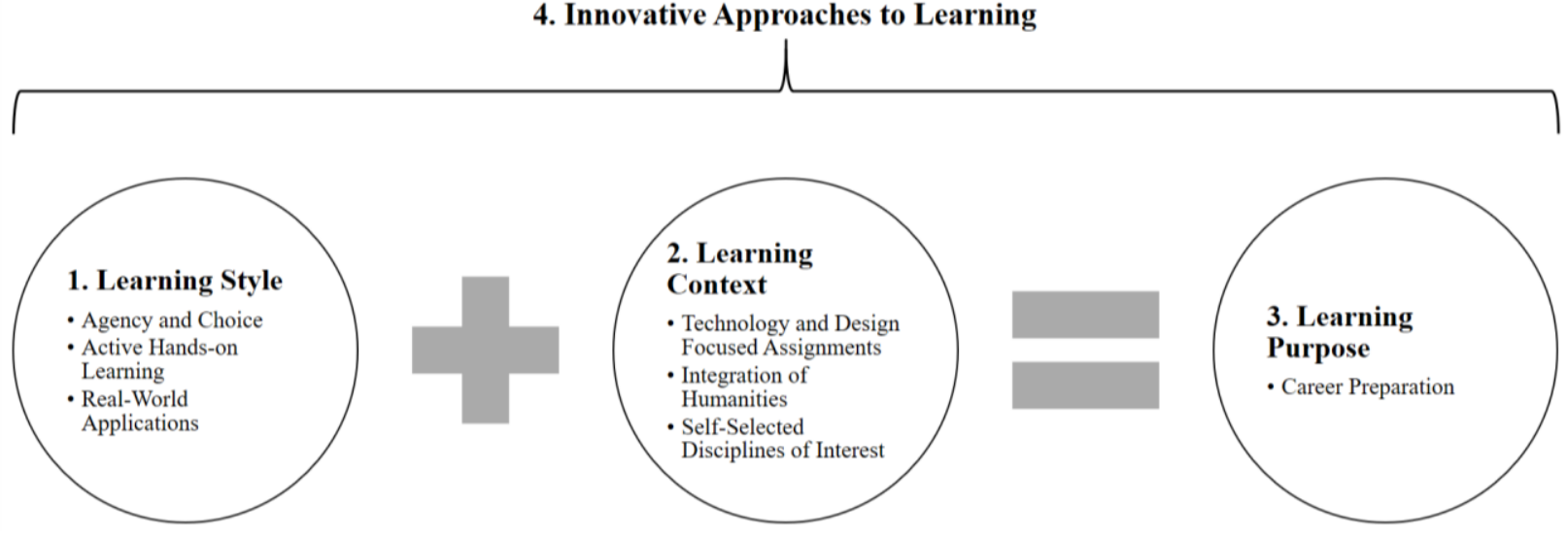

Figure 3: Summarized Findings

\subsection{Benefactors of User-Generated Content}

This story and associated themes, which resulted from user-generated content, has the potential to benefit many different stakeholders throughout campus and beyond. First, administration can benefit from this information. Knowing that students desire the integration and transcendence of multiple topic areas, from technology and design to the humanities, Deans and Department Chairs can use this as motivation for establishing additional new programs within the College and across the University. For example, with this specific bachelor's degree in transdisciplinary studies in technology (TST) students are required to complete 120 credits; about 1/3 of the credits are core TST classes and the remaining credits are chosen by the students, within certain guidelines. One department within the college has already expressed interest in creating a TSET (transdisciplinary studies in ENGINEERING technology) degree. In this case, students would still take the core TST classes (about $1 / 3$ of the credits) but the other credits would follow more closely to the engineering technology curriculum. What about a TSCT (transdisciplinary studies in COMMUNICATIONS technology) degree? Or a TSAT (transdisciplinary studies in AVIATION technology) degree? Knowing that students may have a specialized interest area (for example, in engineering, communications, or aviation), Deans and Department Chairs can create a win-win for increasing enrollment within their specific degrees.

Second, TST faculty can benefit from this information with respect to curriculum design. Student feedback is critical and beneficial for understanding what works and what doesn't work. For example, one of the focus group discussions led to a conversation about software depth versus breadth. Would students prefer to learn one software very well or learn how to use a variety of software platforms at a higher overview level? The discussion suggests that students prefer the prior. As a result, future curriculum is being modified to provide "deep dives" into software to optimize understanding of key features and software outputs.

Third, the staff working in marketing, recruitment, career services and advising can benefit from this information. Understanding what led students to enroll in the program, in that many students simply wanted to do something different, can assist marketing in the development of new program 
materials (e.g., website presence, program fliers, and other marketing materials). In addition, knowing how students heard about the new program is beneficial for recruitment. It can help them plan new recruitment events taking into consideration the motivations, values and mindsets of potential future students. Advising also benefits from this information. It can help advisors guide students towards or away from the new program. For students that are more independent, resourceful, are open to experimenting, and enjoy the integration of STEM and the humanities, the advisors can lead them towards this program. However, for students that prefer more structure and desire depth within a specific discipline, advisors can quickly recognize the potential lack of fit and lead students down a different educational path.

Lastly, and in summary, the students can benefit by sharing this information due to improvements made to the program. Specifically, due to the student requests for additional specialized interest areas, plans are underway for administration to establish new specialized interest areas. These new concentrations or tracks will make it easier for students to take the necessary courses without worrying about pre-requisite requirements. Furthermore, due to the student requests for more in depth software training, versus learning several software programs at a high level, faculty are currently in the process of curriculum redesign to focus more on depth rather than breadth. Finally, students are confident the program will prepare them for entering the workforce. However, students expressed the need for additional language they can use to explain the new program to family members, peers and potential employers. Marketing is currently in the process of developing new program materials and updating the website. In addition, career services is currently developing a career fair to meet the specific needs of transdisciplinary, multidisciplinary, and interdisciplinary type programs.

\section{Conclusion}

\subsection{Summary}

The purpose of this study was to show one approach to the new program development process using students (e.g., the customer) in the data collection process. This approach used participatory research and photo-voice to allow students to act as researchers and actively participate in the data collection and analysis process. In response to the research question, "How can students be used in the information discovery and analysis process associated with new program development?" the authors provided a process for student involvement in the continuous improvement of a new program called transdisciplinary studies in technology. Furthermore, the authors provided recommendations for how university stakeholders can benefit from the user-generated information. Specifically, administrators can use the information to collaborate on new dual degree offerings, faculty can use the information to improve the curriculum design, marketing can use the information to develop new materials, and recruitment and advising can use the information to better understand the motivations, values, and mindsets of potential future students.

\subsection{Future Research}

As noted in the Introduction, future research should continue to investigate how innovation and design processes can be developed and deployed in higher education (Gantogtokh and Quinlan, 2017, Holley, 2009, Richter and Paretti, 2009). New program development is vital for educational 
institutions to stay current with the ever changing industry needs (Wall and Shankar, 2008). Thus, higher education needs to develop new processes for information discovery, analysis, and dissemination. In addition, researchers need to be deliberate and intentional about empirically investigating and validating best practices for new program development.

\section{References}

Becke, S. D. \& Bongard, S. 2018. Using photo elicitation to introduce a network perspective on attachment during middle childhood. International Journal of Qualitative Methods, 17, 1609406918797017.

Borrego, M. \& Newswander, L. K. 2010. Definitions of Interdisciplinary Research: Toward Graduate-Level Interdisciplinary Learning Outcomes. The Review of Higher Education, 61-84.

Brown, T. 2009. Change by design: how design thinking transforms organizations and inspires innovation New York, NY, Harper Collins.

Buck, G. A., Cook, K. L., Quigley, C. F., Prince, P. \& Lucas, Y. 2013. Seeking to improve African American girls' attitudes toward science: A participatory action research project. The Elementary School Journal.

Colombo, G., Dell'era, C. \& Frattini, F. 2015. Exploring the contribution of innovation intermediaries to the new product development (NPD) process: a typology and an empirical study. $R \& D$ Management, 45, 126-146.

Copes, H., Tchoula, W., Brookman, F. \& Ragland, J. 2018. Photo-Elicitation Interviews with Vulnerable Populations: Practical and Ethical Considerations. Deviant Behavior, 39, 475494.

Cowden, C. D. \& Santiago, M. F. 2016. Interdisciplinary Explorations: Promoting Critical Thinking via Problem-Based Learning in an Advanced Biochemistry Class. Journal of Chemical Education, 464.

Drucker, P. F. 1998. The discipline of innovation. Leader to Leader, 1998, 13-15.

Gant, L. M., Shimshock, K., Allen-Meares, P., Smith, L., Miller, P., Hollingsworth, L. A. \& Shanks, T. 2009. Effects of photovoice: Civic engagement among older youth in urban communities. Journal of community practice, 17, 358-376.

Gantogtokh, O. \& Quinlan, K. M. 2017. Challenges of designing interdisciplinary postgraduate curricula: case studies of interdisciplinary master's programmes at a research-intensive UK university. Teaching in Higher Education, 569.

Herbert, K. J., Baize-Ward, A. \& Latz, A. O. 2018. Transformative Pedagogy with Innovative Methodology: Using Photovoice to Understand Community College Students' Needs. Community College Journal of Research and Practice, 536.

Herz, L., Russo, M. J., Ou-Yang, H. D., El-Aasser, M., Jagota, A., Tatic-Lucic, S. \& Ochs, J. 2011. Development of an Interdisciplinary Undergraduate Bioengineering Program at Lehigh University. Advances in Engineering Education, 2.

Holley, K. 2009. The challenge of an interdisciplinary curriculum: a cultural analysis of a doctoraldegree program in neuroscience. The International Journal of Higher Education and Educational Planning, 58, 241-255.

Ivanitskaya, L., Clark, D., Montgomery, G. \& Primeau, R. 2002. Interdisciplinary Learning: Process and Outcomes. Innovative Higher Education, 27, 95-111.

Kelly, K., Lee, S. H. M., Bowen Ray, H. \& Kandaurova, M. 2018. Using the Photovoice Methodology to Increase Engagement and Sharpen Students' Analytical Skills Regarding 
Cultures, Lifestyles, and Markets Internationally. Marketing Education Review. Summer2018, 28, 69.

Knight, D. B., Lattuca, L. R., Kimball, E. W. \& Reason, R. D. 2013. Understanding Interdisciplinarity: Curricular and Organizational Features of Undergraduate Interdisciplinary Programs. Innovative Higher Education, 38, 143-158.

Lattuca, L., Knight, D., Seifert, T., Reason, R. \& Liu, Q. 2017. Examining the Impact of Interdisciplinary Programs on Student Learning. Innovative Higher Education. Aug2017, 337.

Mader, E., Roseamelia, C., Lewis, S., Arthur, M., Reed, E. \& Germain, L. 2016. Clinical training in the rural setting: using photovoice to understand student experiences. Rural And Remote Health [Rural Remote Health] 2016 Apr-Jun, 16.

Mars, M. M. 2015. Interdisciplinary Entrepreneurial Leadership Education and the Development of Agricultural Innovators. Journal of Agricultural Education, 56, 178.

Mcintyre, A. 2007. Participatory action research, Sage Publications.

O'neill, G. \& Mcmahon, S. 2012. Giving Student Groups a Stronger Voice: Using Participatory Research and Action (PRA) to Initiate Change to a Curriculum. Innovations in Education and Teaching International, 161.

Ozanne, J. L. \& Saatcioglu, B. 2008. Participatory action research. Journal of consumer research, 35, 423-439.

Richter, D. M. \& Paretti, M. C. 2009. Identifying barriers to and outcomes of interdisciplinarity in the engineering classroom. European Jouranl Of Engineering Education.

Roberts, D. 2018. The engagement agenda, multimedia learning and the use of images in higher education lecturing: or, how to end death by PowerPoint. Journal of Further \& Higher Education. Nov2018, 42, 969.

Roberts, D. M., Brown, A. M. B. \& Edwards, L. 2015. Participatory Action Research in Two Primary Schools in a Rural Tanzanian Village: An Exploration of Factors to Cultivate Changes in Teaching and Learning. Educational Action Research, 366.

Sattayaraksa, T. \& Boon-Itt, S. 2016. CEO transformational leadership and the new product development process: The mediating roles of organizational learning and innovation culture. Leadership \& Organization Development Journal, 37, 730-749.

Stroud, M. W. 2014. Photovoice as a Pedagogical Tool: Student Engagement in Undergraduate Introductory Chemistry for Nonscience Majors. Journal of College Science Teaching, 43, 98.

Sweet, C., Blythe, H. \& Carpenter, R. Why Design Thinking Should Matter to Higher Education, Part I. The National Teaching \& Learning Forum, 2017. Wiley Online Library, 5-7.

Walker, A., Langdon, J. L., Colquitt, G. \& Mccollum, S. 2017. Using Photovoice to Initiate Improvement in a PETE Program. Journal of Teaching in Physical Education, 36, 83.

Wall, S. \& Shankar, I. 2008. Adventures in transdisciplinary learning. Studies in Higher Education, 551.

Wang, C. \& Burris, M. A. 1997. Photovoice: Concept, methodology, and use for participatory needs assessment. Health education \& behavior, 24, 369-387.

Wang, Q., Li, H., Pang, W., Liang, S. \& Su, Y. 2016. Developing an integrated framework of problem-based learning and coaching psychology for medical education: a participatory research. BMC medical education, 16, 2.

Yasmeen, G. 2016. Action Research: An Approach for the Teachers in Higher Education. Turkish Online Journal of Educational Technology - TOJET, 46. 